\title{
ANÁLISE DE DESEMPENHO ECONÔMICO E SOCIAL: ESTUDO DO BALANÇO SOCIAL DE EMPRESAS BRASILEIRAS
}

\author{
Marcos Antonio Souza \\ Doutor em Controladoria e Contabilidade pela Universidade de São Paulo - USP \\ Professor do Curso de Mestrado em Ciências Contábeis da UNISINOS \\ marcosas@unisinos.br \\ Rochele Medeiros Pimmel \\ Bacharel em Ciências Contábeis pela Unisinos \\ Analista Contábil em Empresa Industrial \\ chelpimmel@yahoo.com.br
}

\begin{abstract}
RESUMO
O objetivo deste artigo é analisar o desempenho da gestão sustentável refletido no Balanço Social de empresas brasileiras. Nesse estudo, assume-se que a sociedade passou a exigir que as empresas, além do lucro, tenham compromisso com ações socioambientais. Trata-se de uma pesquisa aplicada e documental, que busca abordar o problema de forma quantitativa e qualitativa. Dez empresas de diferentes setores econômicos foram selecionadas, cujos dados referentes ao período 2008-2010 foram coletados diretamente das demonstrações contábeis. Os principais resultados indicam que as empresas ainda estão no início da adoção de ações sustentáveis, visto que as ações socioambientais são direcionadas, basicamente, para o cumprimento das obrigações legais. Quanto à distribuição do total do valor adicionado no triênio, o maior beneficiário, de modo geral, foi o governo $(52,5 \%)$, seguido pelos colaboradores $(14,9 \%)$. O Bradesco foi a empresa que apresentou distribuição mais balanceada do valor adicionado ( $\mathrm{R} \$ 55,3$ bilhões): $29,1 \%$ (governo) e $31 \%$ (colaboradores). Além disso, destinou R $\$ 32,9$ bilhões aos investimentos socioambientais: 81,2\% compulsórios e 18,8\% voluntários. Na segunda posição, encontra-se a Sabesp (2011), com a seguinte distribuição: 15,2 bilhões de reais, sendo 30\% para o governo e $28,9 \%$ para os colaboradores. Quanto aos investimentos socioambientais (R\$ 6 bilhões), tem-se: $82,1 \%$ para os compulsórios e $17,9 \% \%$, para os voluntários.
\end{abstract}

Palavras-chave: Balanço social; Gestão socioambiental; Responsabilidade social.

\section{ANALYSIS OF ECONOMIC AND SOCIAL PERFORMANCE: STUDY OF THE SOCIAL BALANCE OF BRAZILIAN COMPANIES}

\begin{abstract}
This paper analyzes the performance of sustainable management reflected in the Social Balance of Brazilian enterprises. For the study, we assume that society has come to require that companies have commitment to social and environmental actions, in addition to being profitable. This applied and documental research uses quantitative and qualitative data to analyze performance. Ten companies from different economic sectors were selected and data were collected directly from financial statements for the period of 2008-2010. The main results show that the companies are still in the early adoption of sustainable actions, since the social and environmental actions result from legal obligations. In general, the biggest beneficiary of total value added was the government $(52.5 \%)$, followed by the employees (14.9\%). Bradesco was the company that made the most balanced distribution of value added $\mathrm{R} \$ 55.3$ billion: $29.1 \%$ (government) and $31 \%$ (employees). In addition, Bradesco allocated $\mathrm{R} \$ 32.9$ billion to social and environmental investments: $81.2 \%$ (compulsory) and $18.8 \%$ (volunteers). In second place is Sabesp (2011), with a distribution of value added R $\$ 15.2$ billion: $30 \%$ (government) and 28.9\% (employees). In addition, Sabesp allocated R\$6 billion to social and environmental investments: $82.1 \%$ (compulsory) and $17.9 \%$ (volunteers).
\end{abstract}

Key words: Social balance; Social \& environmental management; Sustainable development.

Revista de Gestão Social e Ambiental - RGSA, São Paulo, v. 7, n. 1, p. 53-69, jan./abr. 2013. 


\section{INTRODUÇÃO}

A Revolução Industrial, consolidada no século XVIII, alavancou o crescimento econômico, trazendo novas tecnologias e melhorando a qualidade de vida da sociedade. No entanto, os recursos naturais do planeta foram sendo utilizados sem consciência e em larga escala. Assim, o meio ambiente começou a entrar em processo de degradação, apresentando vários problemas, tais como poluição do ar, solo e água; desmatamentos; esgotamento dos recursos naturais; entre outros. Além disso, conforme Tenório (2006) tem-se também as discussões sobre a responsabilidade social das empresas.

Foi a partir da década de 1960, segundo Almeida (2010), que a degradação do meio ambiente tornou-se mais visível, originando as primeiras reações e estudos sobre suas graves consequências para o mundo. Com o crescimento da população e do consumo, alguns recursos passaram a ser mais valorizados, temendo o seu esgotamento futuro. De outra parte, conforme destaca Ponchirolli (2008), a responsabilidade social, nos últimos anos, tem sido bastante difundida, com as empresas passando a enfrentar novos desafios impostos pelos consumidores, e, ao mesmo tempo, pressões estabelecidas pela sociedade e governo com a criação de regras e legislações, normas éticas e trabalhistas, em todo o processo de gestão.

Conforme Moura (2008), as empresas, por serem produtoras de bens e serviços, e consumidoras de recursos, passaram a ter destaque na questão socioambiental. Nesse cenário, a comunidade, as Organizações Não-Governamentais (ONGs), os governos, clientes, fornecedores e investidores trataram de exigir uma postura de melhoria dos processos produtivos, o que resultou em uma menor geração de resíduos e poluentes, na utilização de menor quantidade possível de matérias-primas e energia, além das responsabilidades com as pessoas empregadas e aquelas situadas no entorno de suas atividades.

Na década de 1970, na França, surgiu o Balanço Social com a finalidade de evidenciar o compromisso da empresa com a economia, sociedade e o meio ambiente. No Brasil, debates sobre o Balanço Social ganharam ênfase somente a partir de 1997, com o trabalho do sociólogo Herbert de Souza. Desse modo, a partir dos anos 1990, ações destinadas para a comunidade, ao meio ambiente e aos funcionários, passaram a ser divulgadas (Reis; Medeiros, 2007).

Para Martins, Bernardo e Madeira (2002), o Balanço Social se torna um demonstrativo de grande importância, tanto para análise quanto para a avaliação do desempenho das empresas, pois os investidores e clientes tendem a direcionar recursos e consumir produtos de empresas preocupadas com a ética e a transparência. Por ser uma demonstração contábil, a elaboração do Balanço Social passa a ser, conforme Tinoco (2010), uma atribuição da contabilidade.

O problema de pesquisa que este estudo procura responder é o seguinte: Qual o desempenho da gestão sustentável de empresas brasileiras refletido no seu Balanço Social? Tem-se então como objetivo geral mensurar, analisar e avaliar o desempenho da gestão sustentável de empresas refletido no Balanço Social.

A contribuição deste estudo está em disponibilizar um conjunto de informações passíveis de serem utilizadas para análise do desempenho da gestão sustentável das empresas de diversos setores da economia refletido no Balanço Social. Oportuniza, assim, que vários usuários (governo, associações de classe, sindicatos, agências reguladoras, investidores e etc.) conheçam qual a contribuição das empresas para um desenvolvimento sustentável dela e da sociedade em geral. Pela análise, é possível que cada usuário, tenha informações de seu interesse.

A relevância do tema também pode ser expressa pelo interesse e pelos estudos de vários autores. Entre eles, pode-se citar: Pinto e Ribeiro (2004), Athar Neto (2006), Morimoto e Zen (2006), Costa e Souza (2006), Igarashi et al. (2011), Souza et al. (2011).

Além desta introdução, este estudo contempla outras quatro seções. A primeira delas corresponde à contextualização teórica do tema; na segunda, os aspectos metodológicos da pesquisa; a terceira faz a análise e discussão dos dados e resultados; e, a última seção, apresenta as principais conclusões e recomendações para futuras pesquisas.

Revista de Gestão Social e Ambiental - RGSA, São Paulo, v. 7, n. 1, p. 53-69, jan./abr. 2013. 


\section{REFERENCIAL TEÓRICO}

\subsection{Gestão e Responsabilidade Social}

Atualmente, é possível observar mudanças nos objetivos e nas atuações das empresas, que passaram a incorporar a prática da responsabilidade social na sua gestão (Ponchirolli, 2008). Segundo Tenório (2006), a responsabilidade social nas empresas é um tema da atualidade que envolve, numa visão restrita, desde a geração de lucro pelos empresários e, em um contexto mais abrangente, até a implantação de ações sociais no plano dos negócios.

Até o início do século XX, as corporações tinham apenas o objetivo obter lucro para seus acionistas, afirma Gomes e Moretti (2007). Em 1919, nos Estados Unidos, a questão da responsabilidade social ficou em evidência com o julgamento do caso Dodge versus Ford. Nesse caso, Ford (presidente e acionista majoritário), em 1916, reverteu parte dos dividendos para investimento na capacidade de produção, no aumento de salário e fundo de reserva para redução de receitas, justificando objetivos sociais e, ao mesmo tempo, contrariando os interesses dos irmãos Dodges (acionistas). A Suprema Corte de Michigan foi favorável aos Dodges, justificando que a corporação existe para benefício de seus acionistas, prevalecendo apenas o interesse da empresa na geração de lucro.

De acordo com Ashey (2010), após esse período, a ideia que as empresas deveriam responder apenas aos seus acionistas foi muito criticada, com o tema vindo a público novamente no ano de 1953 com o caso A. P. Smith Manufacturing Company versus Barlow. Nesse caso, a Suprema Corte de Nova Jersey foi favorável a doação de recursos para uma instituição de ensino, o que contrariou os interesses dos acionistas e determinou que a corporação buscasse $o$ desenvolvimento social, estabelecendo em lei a filantropia corporativa. Em seguida, ainda conforme a autora, essa decisão passou a ser utilizada por defensores da responsabilidade social, a fim de que outras ações sociais e ambientais, mesmo não tendo retorno financeiro, pudessem ser adotadas pela organização. Na década de 1960, tiveram início as discussões sobre a importância da responsabilidade social corporativa nos Estados Unidos e, no final da década, também na Europa.

Ashley (2010) acrescenta que, no Brasil, a responsabilidade social empresarial iniciou seu desenvolvimento no final da década de 1990, época em que foram criados os institutos e as fundações relacionados a essas questões, tais como o Instituto Ethos, Instituto de Cidadania Empresarial - ICE; Conselho de Cidadania Empresarial da Federação das Indústrias do Estado de Minas Gerais - FIEMG; Núcleo de Ação Social - NAS; Grupo de Institutos, Fundações e Empresas - GIFE; Associação de Empresários pela Cidadania (Cives); Adce-Brasil, Fundação Instituto de Desenvolvimento Empresarial e Social - Fides.

Para Carroll (1991), responsabilidade social compreende as dimensões econômicas, legais, éticas e filantrópicas (Figura 2), conceito que continua como um dos mais citados. A responsabilidade econômica é a principal, estando todas as demais condicionadas a esta, já que, antes de qualquer coisa, a empresa deve gerar lucro. Em seguida, vem a responsabilidade legal, pois, após a empresa definir seu sistema econômico deve se submeter às regras básicas impostas pela sociedade. Em terceiro, aparece a responsabilidade ética, incluídas ai as normas que não estão previstas no aspecto econômico e legal, referindo-se a obrigação de fazer o que é certo e justo, evitando ou minimizando os danos à sociedade. Na ponta da pirâmide aparece a responsabilidade filantrópica, abrangendo as ações e os programas em resposta às expectativas da sociedade, devendo as empresas atuar como boas cidadãs. 


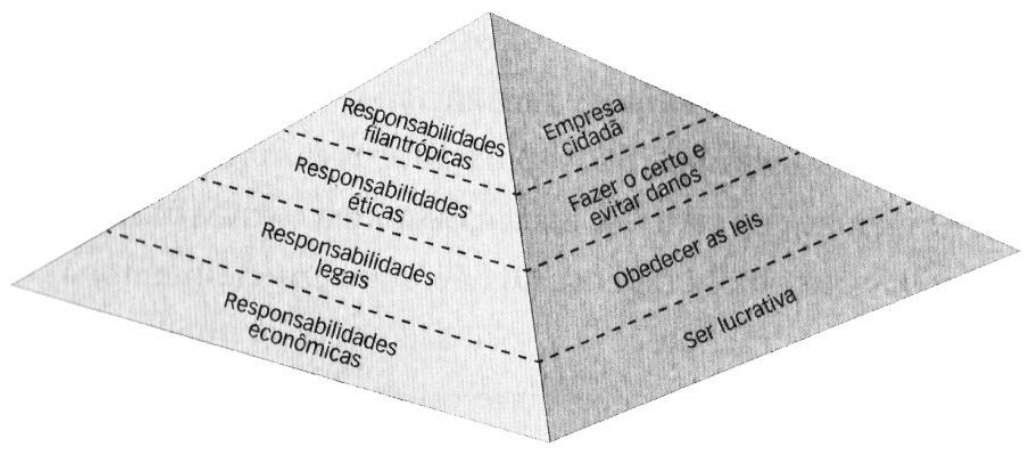

Figura 1 - Pirâmide da Responsabilidade Social de Carroll

Fonte: Carroll (1991)

Para Dias (2009), com a responsabilidade social surgiu uma nova forma de a empresa agregar valor à sua imagem e conquistar mercados. Neste novo cenário, buscar apenas o lucro econômico passou a não mais ser suficiente, sendo também importante a organização se engajar em projetos e atividades voltadas para o social, com o intuito de proporcionar o bem-estar aos seus funcionários e à comunidade.

\begin{tabular}{|c|c|c|}
\hline \multicolumn{3}{|c|}{ Sustentabilidade Emp resarial } \\
\hline Ambiental & Social & Financeiro \\
\hline $\begin{array}{l}\text { Cuidados complaneta } \\
\text {-Proteção ambiental } \\
\text { - Recursos renováveis } \\
\text { - Ecoeficiência } \\
\text { - Gestäo de resíduos } \\
\text { - Gestäo de Riscos }\end{array}$ & $\begin{array}{c}\text { Dignidade humana } \\
\text {-Direitos humanos } \\
\text { - Direitos trabalhadores } \\
\text { - Envolvimento comunidade } \\
\text { - Transparência } \\
\text { - Postura ética }\end{array}$ & $\begin{array}{c}\text { Prosperidade } \\
\text {-Resultado econômico } \\
\text { - Direitos dos acionistas } \\
\text {-Competitividade } \\
\text { - Relaçäo entre clientes } \\
\text { e fomecedores }\end{array}$ \\
\hline
\end{tabular}

Figura 2- Tripé da sustentabilidade

Fonte: Adaptado de Tinoco (2010, p.15)

O conteúdo da figura 2 consiste na necessidade de as empresas ajustarem suas decisões estratégicas nas dimensões da sustentabilidade empresarial, ou seja, a empresa deve se manter de forma positiva nas três esferas da sustentabilidade: social, ambiental e financeiro (Tinoco, 2010). Para o autor, esse tripé pode ser evidenciado da seguinte forma:

a) Social: são os integrantes da empresa, para os quais deve-se assegurar as condições plenas de trabalho seguro, oportunidades de realização de planos de vida e o direito de partilhar os resultados que produzem. Também se refere às comunidades com as quais interage, oferecendo contribuição necessária à superação suas carências;

b) Ambiental: a empresa deve suavizar o impacto que sua atividade possa causar à natureza e ir além, participando do combate às ameaças atuais;

c) Econômico: a empresa deve cumprir os compromissos essenciais à sua atividade e gerar resultados, assegurando a sua continuidade com o retorno dos investimentos.

\subsection{Atuação social da Empresa}

As empresas têm incorporado ações sociais às suas atividades, seja por exigência da sociedade, seja para conquistar e manter seus consumidores, que, por sua vez, são cada vez mais exigentes em toda a cadeia produtiva da organização. 
De acordo com Goldstein (2007, p. 42), “[...] responsabilidade social não é sinônimo de ação social", sendo ela mais ampla. Ela abrange, além das ações voltadas para comunidade e o ambiente, também ações para todos os públicos relacionados à empresa, tais como acionistas, funcionários, clientes, fornecedores e poderes públicos. As empresas encontram-se num processo de transição em relação a sua forma de atuação social, de um padrão individual para um que evidencia a coletividade. É possível, conforme Tenório (2006), destacar algumas tendências dessa nova forma de atuação: (a) profissionalização do processo como um todo; (b) atuações voluntárias; (c) projetos coletivos para desenvolver o empreendedorismo social.

Segundo Tenório (2006), apesar da inclusão da ação social no modelo de gestão das empresas, algumas expressões ainda não estão bem definidas, sendo até mesmo utilizadas como sinônimos. Assim, faz-se necessário sua conceituação, como segue:

a. Filantropia empresarial: é caracterizada por uma ação assistencialista, caridosa e geralmente temporária, porém, quando praticada, não assegura que a empresa esteja agindo simultaneamente em favor do meio ambiente e da sociedade.

b. Cidadania empresarial: é caracterizada pela participação ativa da empresa na sociedade, participando das decisões e ações no espaço público que se insere.

c. Responsabilidade social corporativa: é caracterizada pelo desenvolvimento da empresa, pela busca da melhoria da qualidade de vida da sociedade e preservação do meio ambiente.

Portanto, na gestão da responsabilidade social, a empresa tende a fazer e acompanhar seus investimentos de maneira estratégica, proporcionando melhor qualidade de vida para a sociedade, além de preservar o meio ambiente. A ênfase na divulgação dessas ações, dando visibilidade para sua atuação social, contribui em trazer mais desenvolvimento econômico.

Dias (2009) esclarece que foram criadas normas para certificar as empresas de seu compromisso com a responsabilidade social. Pode-se destacar a norma elaborada, em 1997, pela Social Accountability International (SAI), denominada Responsabilidade Social 8000 (SA8000). Essa norma se baseia no cumprimento das leis trabalhistas e seu sistema de controle pode ser aplicado em empresas de qualquer porte. Essa certificação valida às demonstrações contábeis da empresa e aumenta sua confiabilidade, tendo em vista que muitas empresas já exigem essa certificação de sua cadeia produtiva. Dias (2009) acrescenta que no Brasil, em 2004, a Associação Brasileira de Normas Técnicas (ABNT) criou a norma NBR 16001, que estabelece requisitos mínimos para um sistema de gestão de responsabilidade social. A norma não é obrigatória e com ela é possível verificar se a empresa segue boas práticas de governança, práticas leais de concorrência, compromisso com desenvolvimento profissional, proteção ao meio ambiente, ações sociais de interesse público, entre outros.

De acordo com Instituto Nacional de Metrologia, Qualidade e Tecnologia - Inmetro (2010), em 2010, foi publicada a Norma Internacional ISO 26000 - Diretrizes sobre Responsabilidade Social, fornecendo informações referentes à responsabilidade social, tais como conceito, tendência, princípios e práticas, temas e questões centrais, integração e implantação, compromisso e desempenho, entre outras. A ISO 26000:2010 pode ser aplicada em todos os tipos de organização, sendo de uso voluntário, porém não certificada.

\subsection{Balanço social}

Conforme Tinoco (2008), em seu início, as informações contábeis destinavam-se ao seu usuário principal: proprietário ou gestor. O desenvolvimento econômico motivou investidores a se interessarem pelas informações contábeis para aferir a situação financeira da empresa. Na década de 1960, na Europa e nos Estados Unidos, informações sobre desempenho econômico e social passaram a ser exigidas pelos trabalhadores, trazendo aumento nas informações da empresa, inclusive as da responsabilidade social. Em 1977, na França, criou-se o Balanço Social, que evidenciava basicamente aspectos sociais.

Revista de Gestão Social e Ambiental - RGSA, São Paulo, v. 7, n. 1, p. 53-69, jan./abr. 2013. 
No Brasil, os primeiros Balanços Sociais foram divulgados no final dos anos 1980, após a Fides criar um modelo. Em 1998, o Instituto Brasileiro de Análises Sociais e Econômicas (IBASE) lançou o Selo Balanço Social IBASE/Betinho, atribuído a todas as empresas que publicam o Balanço Social; com esse selo, as empresas evidenciam o compromisso com a responsabilidade social. Nesse mesmo ano, foi criado o Instituto Ethos de Responsabilidade, que atua na responsabilidade social empresarial e sua divulgação. Portanto, a partir da década de 1990, as empresas passaram a divulgar suas ações em relação aos funcionários, ao meio ambiente e a comunidade (Reis; Medeiros, 2007).

O Balanço Social, para Kroetz (2000), representa a demonstração dos gastos e das influências das entidades na promoção humana, social e ecológica, dirigidos aos gestores, aos empregados e à comunidade com que interage no espaço temporal passado/presente/futuro. Tem-se então que o Balanço Social surgiu para evidenciar a responsabilidade social da empresa, tornandose um instrumento importante para análise de sua gestão social.

Para Tinoco (2010), a importância do Balanço Social decorre do enfoque atual de que só a visão do lucro não é mais suficiente para a empresa alcançar seus objetivos. Em longo prazo, para haver continuidade, é necessário que ela atenda as necessidades de todos os envolvidos: clientes, fornecedores, investidores, governos, comunidade, funcionários etc.

\subsection{Contabilidade ambiental}

Para que houvesse a integridade de dados e informações dos aspectos econômico e do meio ambiente, surge a contabilidade ambiental que se torna um mecanismo importante para o desenvolvimento das empresas no mundo globalizado. Ela foi desenvolvida pela necessidade de oferecer informações adequadas às características de uma gestão ambiental. Conforme Ferreira (2003), ela não se refere a uma nova contabilidade e sim a uma especialização.

Para Ribeiro (2005, p. 45), o objetivo da contabilidade ambiental é "[...] identificar, mensurar e esclarecer os eventos e transações econômico-financeiros que estejam relacionados com a proteção, preservação e recuperação ambiental [...] visando a evidenciação da situação patrimonial de uma entidade". Conforme Carvalho (2008), a inserção das informações ambientais na contabilidade ocorreu na década de 1990, mais especificamente com a ECO/92 que estabeleceu uma agenda internacional de cooperação, visando o desenvolvimento sustentável. Em 1996, a Dinamarca passou a determinar que as empresas que impactam o meio ambiente, apresentem um relatório ambiental. Na Noruega foi promulgada a Lei da Contabilidade Norueguesa, em 1999, que obrigava as empresas a informar sobre o seu ambiente de trabalho e sua relação com ambiente externo.

Conforme Carvalho (2008) em 1995, na 13 ${ }^{a}$ sessão do Grupo Intergovernamental de Especialistas em Padrões Internacionais de Contabilidade, apresentou-se pesquisa em 55 países sobre o tratamento contábil da questão ambiental. Naquela ocasião, constatou-se que a Bulgária, desde 1992, tem a contabilidade ambiental como parte da contabilidade oficial das empresas; a França desenvolveu um balanço patrimonial ecológico, relacionando as informações apresentadas pela empresa e o meio ambiente; na Holanda, embora não fosse obrigatório, geralmente as empresas demonstravam os riscos ambientais, os impactos ambientais e os esforços para reduzi-los.

Carvalho (2008) acrescenta que a contabilidade ambiental teve início no Brasil em 1996, com a edição da NPA 11 - Balanço e Ecologia, pelo Instituto Brasileiro de Contabilidade IBRACON, com o objetivo de promover a junção da Contabilidade e o Meio Ambiente.

\subsection{Indicadores da gestão sustentável}

Todas as empresas, do tipo sociedade anônima, de capital aberto ou fechado, pública ou privada, independentemente do seu porte, são obrigadas, por lei, a divulgar informações financeiras que possibilitem medir o seu desempenho, conforme afirma Alessio (2004).

Além dessa obrigatoriedade, é possível observar, nas últimas décadas, o desenvolvimento de indicadores e instrumentos que permitem medir também o comportamento socialmente responsável

Revista de Gestão Social e Ambiental - RGSA, São Paulo, v. 7, n. 1, p. 53-69, jan./abr. 2013. 
das empresas, já que essa medição passou a exigir transparência e responsabilidade social tanto quanto o foco financeiro (Alessio, 2004).

Reis e Medeiros (2007) destacam que uma das demonstrações utilizadas para avaliar o desempenho da empresa é o balanço social, o qual reúne as informações sobre as atividades socioambientais que a empresa realiza, tendo em vista o bem-estar da sociedade e a preservação do meio ambiente. Assim como um balanço contábil, no social as informações e os indicadores são mensurados, interpretados e apresentados em forma de um relatório.

Tenório (2006) acrescenta que a demonstração do valor adicionado (DVA) pode ser outro instrumento de avaliação do desempenho, por ser um relatório que permite identificar quanto de valor uma empresa agrega à sociedade e de que forma ele é repartido entre os agentes, ou seja, quem são os beneficiados com o desempenho da empresa. Entre tais beneficiários incluem-se os empregados (salários, gratificações, honorários, participação nos resultados), governo (impostos diretos e indiretos), terceiros (juros e aluguéis), acionistas (dividendos e lucros retidos). Na busca de melhoria de decisões, ações e práticas sustentáveis das empresas, Alessio (2004, p. 88) afirma que

[...]algumas organizações da sociedade já foram criadas especialmente para trabalhar com as empresas na adoção da responsabilidade social e vários indicadores, instrumentos normativos e auditorias já possibilitam mensurar o desempenho social das empresas, além de também serem uma forma de nortear e aperfeiçoar as ações de responsabilidade social já adotadas .

Para Bellen (2006), o objetivo dos indicadores é agregar e quantificar informações de modo que sua significância fique mais aparente. As principais funções dos indicadores são: (a) avaliação de condições e tendência; (b) comparação entre lugares e situações; (c) avaliação de condições e tendências em relação às metas e aos objetivos; (d) prover informações de advertência; (e) antecipar futuras condições e tendências. $\mathrm{O}$ autor ressalta que os indicadores devem ser compreensíveis, transparentes e os seus usuários precisam ser estimulados a compreender seu significado de acordo com seus próprios valores.

\section{6 Índices de Análise do Balanço Social}

Mesmo não havendo obrigatoriedade legal para publicação do balanço social, o modelo mais utilizado no Brasil é o do IBASE. Athar Neto (2006) destaca que o modelo apenas evidencia os valores aplicados em cada indicador, dificultando a análise, compreensão e interpretação dos dados por seus usuários.

Athar Neto (2006) sugere ainda que, para melhor análise, pode-se usar uma forma parecida à da análise tradicional de balanço, criando índices a partir dos indicadores informados no balanço social. O autor subdivide os indicadores em oito grupos (Figura 3).

\begin{tabular}{|c|l|l|}
\hline Ordem & Grupo & \multicolumn{1}{c|}{ Denominação } \\
\hline 1 & GPRV & Grau de Participação da Receita Líquida de Vendas \\
\hline 2 & GPRO & Grau de Participação do Resultado Operacional \\
\hline 3 & GPIS & Grau de Participção dos Indicadores Sociais e Ambientais \\
\hline 4 & RISI & Relação dos Indicadores Sociais Internos \\
\hline 5 & RISE & Relação dos Indicadores Sociais Externos \\
\hline 6 & RISA & Relação dos Indicadores Ambientais \\
\hline 7 & RICV & Relação dos Indicadores Compulsórios e Voluntários \\
\hline 8 & RIL & Relação dos Indicadores Laborais \\
\hline
\end{tabular}

Figura 3 - Grupos de Indicadores de Análise do Balanço Social

Fonte: Athar Neto (2006).

Os grupos indicados na figura 3 são desmembrados em 15 indicadores específicos, detalhados na Figura 4.

Revista de Gestão Social e Ambiental - RGSA, São Paulo, v. 7, n. 1, p. 53-69, jan./abr. 2013. 
Análise de desempenho econômico e social: estudo do balanço social de empresas brasileiras

\begin{tabular}{|c|c|c|}
\hline $\begin{array}{l}\text { Grupo/ } \\
\text { Índice } \\
\end{array}$ & Fórmula & Significado (Relações) \\
\hline GPRV 1 & $\begin{array}{l}\text { (Indicadores sociais internos + Indicadores sociais exterr } \\
\text { + Indicadores ambientais) / Receita líquida venda }\end{array}$ & $\begin{array}{l}\text { Investimento em responsabilidade soci } \\
\text { em relação à receita de vendas }\end{array}$ \\
\hline GPRO 2 & $\begin{array}{l}\text { Resultado Operacional / (Indicadores Sociais Internos + } \\
\text { Indicadores sociais externos + Indicadores ambientais) }\end{array}$ & $\begin{array}{l}\text { Retorno econômico proporcionado pelos } \\
\text { investimentos em responsabilidade social }\end{array}$ \\
\hline GPIS 3 & $\begin{array}{l}\text { Indicadores Sociais Internos / (Indicadores Sociais Internos } \\
\text { + Indicadores Soc. Externos + Indicadores Ambientais) }\end{array}$ & 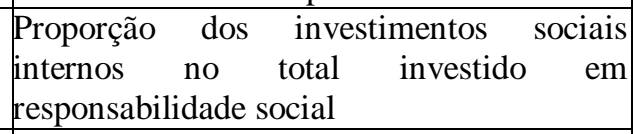 \\
\hline GPIS 4 & $\begin{array}{l}\text { Indicadores sociais externos / (Indicadores sociais } \\
+ \text { Indicadores sociais externos + Indicadores ambie }\end{array}$ & 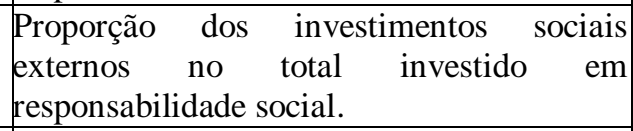 \\
\hline GPIS 5 & $\begin{array}{l}\text { Indicadores Am } \\
\text { Indicadores soci }\end{array}$ & $\begin{array}{l}\text { Proporção dos investimentos ambientais nc } \\
\text { total investido em responsabilidade social. }\end{array}$ \\
\hline RISI 6 & Indicadores laborais / Indicadores sociais int & $\begin{array}{l}\text { ão dos indicadores laborais no total } \\
\text { lo em indicadores sociais internos }\end{array}$ \\
\hline RISI 7 & Remuneração indireta / Indicadores sociais int & $\begin{array}{l}\text { ção remuneração indireta no total } \\
\text { do em indicadores sociais. internos }\end{array}$ \\
\hline RISE 8 & $\begin{array}{l}\text { Tribu } \\
\text { Exter }\end{array}$ & \begin{tabular}{lllll|} 
ção dos tributos no total dos \\
lores externos
\end{tabular} \\
\hline RISE 9 & $\begin{array}{l}\text { Cont } \\
\text { exter }\end{array}$ & $\begin{array}{l}\text { ão das contribuições à sociedade no } \\
\text { indicadores externos }\end{array}$ \\
\hline RISA 10 & os relacionados cor & $\begin{array}{l}\text { ção dos investimentos na produçãc } \\
\text { investido em meio ambiente }\end{array}$ \\
\hline RIS & $\begin{array}{l}\text { Investimentos em programas externos / Investimento total } \\
\text { em meio ambiente }\end{array}$ & \begin{tabular}{llrr} 
Proporção investimento em & \multicolumn{2}{c}{ Programas } \\
Externos na Produção no & Total de \\
Investimento em meio ambiente & & \\
\end{tabular} \\
\hline & $\begin{array}{l}\text { Indicadores sociais compulsórios / Total investimento } \\
\text { social }\end{array}$ & $\begin{array}{l}\text { Proporção de Indicadores Sociais } \\
\begin{array}{l}\text { Compulsórios no total do investimento } \\
\text { social }\end{array}\end{array}$ \\
\hline RICV 13 & Indicadores sociais voluntários / Total i & $\begin{array}{|lcc|}\text { Proporção de indicadores } & \text { sociais } \\
\text { voluntários no total do investimento social }\end{array}$ \\
\hline RIL 14 & Folga pagamento bruto / Rece & $\begin{array}{l}\text { Proporção receita total alocada como } \\
\text { remuneração aos colaboradores }\end{array}$ \\
\hline RIL 15 & Participação nos lucros / Resultado op & $\begin{array}{l}\text { ão do resultado que foi distrik } \\
\text { boradores }\end{array}$ \\
\hline
\end{tabular}

Figura 4 - Detalhamento de Indicadores de Análise do Balanço Social

Fonte: Athar Neto (2006)

\section{PRINCIPAIS ASPECTOS METODOLÓGICOS}

\subsection{Classificações da pesquisa}

De acordo com Silva e Menezes (2001), as pesquisas podem ser classificadas quanto à natureza, forma de abordagem do problema, objetivos e procedimentos técnicos.

Quanto à natureza, a pesquisa é classificada como aplicada, por abordar situações reais, gerando conhecimento prático, ou seja, consiste em analisar Balanços Sociais divulgados por empresas para identificar o desempenho em sua gestão sustentável. Quanto à forma de abordagem do problema, esta pesquisa é considerada quantitativa dada a mensuração dos indicadores, e qualitativa, dada as análises interpretativas de tais indicadores.

Referindo-se aos objetivos, esta pesquisa é classificada como descritiva, tendo em vista o objetivo de descrever, pela análise de indicadores, o comportamento das empresas, evidenciando suas ações sustentáveis, bem como seus investimentos nessas atividades. Quanto aos procedimentos técnicos, esta pesquisa é documental, elaborada a partir de dados e informações coletadas nos Balanços Sociais das empresas disponibilizados nos seus sítios. 


\subsection{Sujeitos da pesquisa}

Esta pesquisa foi realizada com dez empresas brasileiras de capital aberto e de diversos setores da economia brasileira: alimentos processados, energia elétrica, intermediação financeira, madeira, material de transporte, petróleo, saneamento, serviços financeiros, siderurgia e telecomunicação.

A seleção das empresas baseou-se na disponibilidade em endereço eletrônico dos Balanços Sociais dos anos de 2008, 2009 e 2010, em empresas de diferentes setores, possibilitando verificar se há diferenças substanciais em seus desempenhos. Além disso, se é uma empresa aberta, ou seja, com ações negociadas em bolsa de valores.

\subsection{Coleta e tratamento dos dados}

Os dados foram coletados nos Balanços Sociais, do triênio 2008-2010, disponibilizados pelas empresas em seus respectivos sítios. Considerando a inflação dos anos estudados, fez-se o reajuste do valor de cada ano para o último ano analisado, 2010. Utilizou-se o Índice Geral de Preços de Mercado (IGP-M), calculado pela Fundação Getúlio Vargas, conforme Portal Brasil (2011). A atualização monetária foi realizada da seguinte forma:

a. O ano de 2008 foi reajustado com base em seis meses da inflação anual do ano; o valor obtido foi reajustado pela deflação de 2009 e corrigido pela inflação de 2010.

b. O ano de 2009, inicialmente, foi reajustado com base nos seis meses da deflação anual de 2009; posteriormente, foi corrigido pela inflação do ano de 2010;

c. $\mathrm{O}$ ano de 2010 foi reajustado com base nos seis meses da inflação anual do ano;

d. Após corrigir todos os valores de todos os anos, eles foram somados para compor o total corrigido do triênio.

\subsection{Procedimentos de análise dos dados}

A análise foi baseada em valores representativos do triênio 2008 a 2010, corrigidos monetariamente conforme já esclarecido na seção 3.3. Deste modo, não há análise individual de cada ano do triênio, mas sim deles no seu conjunto trienal.

Para fins de análise, compreensão e interpretação dos dados, foram aplicados os índices de análise do Balanço Social, estudados por Athar Neto (2006), expostos na seção 2.6 deste estudo. Ao final, foi feita análise da distribuição do valor adicionado pelas empresas.

\section{APRESENTAÇÃO E ANÁLISE DOS DADOS}

Apresenta-se, na Figura 5, a identificação geral das empresas estudadas: denominação, segmento, fundação, controle acionário.

\begin{tabular}{|c|c|c|c|}
\hline Denominação & Segmento & Fundação & Controle Acionário \\
\hline Brasil Foods & Alimentos processados & 2009 & Privado Nacional \\
\hline Cemig & Energia elétrica & 1952 & Governamental \\
\hline Bradesco & Intermediação financeira & 1943 & Privado Nacional \\
\hline Duratex & Madeira & 1950 & Privado Nacional \\
\hline Embraer & Material Transporte & 1969 & Privado Estrangeiro \\
\hline Petrobras & Petróleo & 1953 & Governamental \\
\hline Sabesp & Saneamento & 1973 & Governamental \\
\hline Redecard & Serviços Financeiros & 1996 & Privado Nacional \\
\hline Usiminas & Siderurgia & 1956 & Privado Nacional \\
\hline TIM & Comunicação & 2002 & Privado Estrangeiro \\
\hline
\end{tabular}

Figura 5 - Empresas analisadas

Fonte: Dados da pesquisa

Revista de Gestão Social e Ambiental - RGSA, São Paulo, v. 7, n. 1, p. 53-69, jan./abr. 2013. 


\section{1 Índices do Balanço Social}

Para uma melhor análise do Balanço Social de cada empresa, bem como o desempenho da sua gestão sustentável, foram utilizados os índices de análise estudados por Athar Neto (2006). Os dados monetários estão apresentados em milhões de reais.

\begin{tabular}{|c|c|c|c|c|c|}
\hline Empresa & $\begin{array}{c}\text { Total Inv } \\
\text { Soc./Amb. }\end{array}$ & Rec. Líq & Res. Operac & $\begin{array}{c}\text { Índice 1 } \\
\text { GPRV (\%) }\end{array}$ & $\begin{array}{c}\text { Índice 2 } \\
\text { GPRO (\%) }\end{array}$ \\
\hline Brasil Foods & 12.152 & 72.411 & 3.537 & 16,8 & 29,1 \\
\hline Cemig & 26.163 & 38.982 & 11.025 & 67,1 & 42,1 \\
\hline Bradesco & 32.919 & 68.912 & 35.553 & 47,8 & 108,0 \\
\hline Duratex & 2.340 & 7.218 & 1.610 & 32,4 & 68,8 \\
\hline Embraer & 3.177 & 31.197 & 2.588 & 10,2 & 81,5 \\
\hline Petrobras & 308.677 & 673.544 & 117.898 & 45,8 & 38,2 \\
\hline Sabesp & 6.010 & 26.493 & 6.501 & 22,7 & 108,0 \\
\hline Redecard & 3.184 & 7.799 & 6.419 & 40,8 & 201,6 \\
\hline Usiminas & 11.904 & 43.748 & 8.828 & 27,2 & 74,2 \\
\hline TIM & 15.779 & 44.856 & 2.010 & 35,2 & 12,7 \\
\hline
\end{tabular}

Figura 6 - Grau de Participação Receita Líquida (GPRV) e Resultado Operacional (GPRO)

Fonte: Dados da pesquisa

Os dados da Figura 6 apresentam o quanto foi investido nos indicadores sociais e ambientais em relação à receita líquida (GPRV), e a representatividade do resultado operacional em relação aos investimentos em indicadores sociais e ambientais (GPRO), durante o triênio. Quanto ao Índice 1, observa-se que a empresa que apresenta a melhor relação foi a Cemig, com 67,1\% da receita, no montante de R \$26,2 bilhões. Em segundo lugar, encontra-se o Bradesco (2011), com 47,8\% e montante de $\mathrm{R} \$ 32,9$ bilhões investidos em ações socioambientais. De outra parte, a empresa que apresentou a menor relação foi a Embraer (2011), com 10,2\%.

Quanto ao Índice 2, o melhor retorno econômico financeiro em relação aos investimentos sociais e ambientais foi da Redecard (2011), com 201,6\% do total de R \$6,4 bilhões. Em segundo lugar, tem-se a Sabesp (2011) e o Bradesco (2008; 2011), ambas com retorno de $108 \%$.

\begin{tabular}{|c|c|c|c|c|c|c|}
\hline Empresa & $\begin{array}{c}\text { Indicad Soc } \\
\text { Internos }\end{array}$ & $\begin{array}{c}\text { Indicad Soc } \\
\text { Externos }\end{array}$ & $\begin{array}{c}\text { Indicad } \\
\text { Ambient }\end{array}$ & $\begin{array}{c}\text { Índice 3 } \\
\text { GPIS (\%) }\end{array}$ & $\begin{array}{c}\text { Índice 4 } \\
\text { GPIS (\%) }\end{array}$ & $\begin{array}{c}\text { Índice 5 } \\
\text { GPIS (\%) }\end{array}$ \\
\hline Brasil Foods & 3.631 & 8.128 & 393 & 29,9 & 66,9 & 3,2 \\
\hline Cemig & 3.052 & 22.839 & 272 & 11,7 & 87,3 & 1,0 \\
\hline Bradesco & 12.532 & 20.294 & 93 & 38,1 & 61,6 & 0,3 \\
\hline Duratex & 706 & 1.588 & 47 & 30,2 & 67,9 & 2,0 \\
\hline Embraer & 2.409 & 737 & 31 & 75,8 & 23,2 & 1,0 \\
\hline Petrobras & 33.381 & 268.306 & 6.990 & 10,8 & 86,9 & 2,3 \\
\hline Sabesp & 1.409 & 4.539 & 71 & 23,4 & 75,4 & 1,2 \\
\hline Redecard & 268 & 2.916 & 0 & 8,4 & 91,6 & 0,0 \\
\hline Usiminas & 2.719 & 8.593 & 592 & 22,8 & 72,2 & 5,0 \\
\hline TIM & 899 & 14.880 & 1 & 5,7 & 94,3 & 0,0 \\
\hline
\end{tabular}

Figura 7 - Grau de Participação dos Indicadores Sociais e Ambientais (GPIS)

Fonte: Dados da pesquisa

A Figura 7 apresenta os dados do GPIS, ou seja, o grau de participação de cada indicador social e ambiental em relação ao montante investido. No índice 3, que indica quanto foi investido nos indicadores sociais internos, a empresa com maior relação percentual foi a Embraer, 75,8\% do total investido, $\mathrm{R} \$ 3,2$ bilhões. Em seguida, no Índice 4, que evidencia a relação dos indicadores sociais externos, a com maior percentual foi a Tim (2011), com 94,3\% do montante de R\$15,2 bilhões. No Índice 5, que revela a relação dos indicadores ambientais, a Usiminas (2011) tem o maior percentual, 5,0\% do total de $\mathrm{R} \$ 11,9$ bilhões investimentos.

Revista de Gestão Social e Ambiental - RGSA, São Paulo, v. 7, n. 1, p. 53-69, jan./abr. 2013. 


\begin{tabular}{|c|c|c|c|c|c|}
\hline Empresa & $\begin{array}{c}\text { Indic } \\
\text { Laborais }\end{array}$ & $\begin{array}{c}\text { Remuner } \\
\text { Indireta }\end{array}$ & $\begin{array}{c}\text { Indic Soc } \\
\text { Internos }\end{array}$ & $\begin{array}{c}\text { Índice 6 RISI } \\
(\mathbf{\%})\end{array}$ & $\begin{array}{c}\text { Índice 7 RISI } \\
(\boldsymbol{\%})\end{array}$ \\
\hline Brasil Foods & 2.301 & 1.330 & 3.631 & 63,4 & 36,6 \\
\hline Cemig & 1.868 & 1.184 & 3.052 & 61,2 & 38,8 \\
\hline Bradesco & 6.916 & 5.617 & 12.532 & 55,2 & 44,8 \\
\hline Duratex & 528 & 177 & 706 & 74,9 & 25,1 \\
\hline Embraer & 1.732 & 677 & 2.409 & 71,9 & 28,1 \\
\hline Petrobras & 21.128 & 12.253 & 33.381 & 63,3 & 36,7 \\
\hline Sabesp & 519 & 890 & 1.409 & 36,8 & 63,2 \\
\hline Redecard & 199 & 68 & 268 & 74,5 & 25,5 \\
\hline Usiminas & 1.530 & 1.190 & 2.719 & 56,2 & 43,8 \\
\hline TIM & 525 & 374 & 899 & 58,4 & 41,6 \\
\hline
\end{tabular}

Figura 8 - Relação dos Indicadores Sociais Internos (RISI)

Fonte: Dados da Pesquisa

Os dados da Figura 8 revelam como os recursos investidos em indicadores sociais internos foram distribuídos (RISI). No índice 6, que revela quanto foi aplicado em indicadores laborais (encargos sociais compulsórios e participação nos lucros), a empresa com maior percentual de investimento foi a Duratex (2011), com 74,9\% do investimento total de R \$ 706 milhões. Em relação ao que foi aplicado em remuneração indireta (capacitação profissional, saúde, educação, outros), calculado pelo índice 7, a empresa com maior percentual foi a Sabesp (2011), investindo 63,2\% do investimento total de R\$1,4 bilhões.

\begin{tabular}{|c|c|c|c|c|c|}
\hline Empresa & $\begin{array}{c}\text { Índices } \\
\text { Laborais }\end{array}$ & $\begin{array}{c}\text { Remuner. } \\
\text { Indireta }\end{array}$ & $\begin{array}{c}\text { Índice Soc } \\
\text { Externos }\end{array}$ & $\begin{array}{c}\text { Índice 6 RISE } \\
(\boldsymbol{\%})\end{array}$ & $\begin{array}{c}\text { Índice 7 RISE } \\
(\boldsymbol{\%})\end{array}$ \\
\hline Brasil Foods & 8.121 & 7 & 8.128 & 99.9 & 0,1 \\
\hline Cemig & 22.655 & 184 & 22.839 & 99,2 & 0,8 \\
\hline Bradesco & 19.800 & 494 & 20.294 & 97,6 & 2,4 \\
\hline Duratex & 1.584 & 4 & 1.588 & 99,7 & 0,3 \\
\hline Embraer & 695 & 41 & 737 & 94,4 & 5,6 \\
\hline Petrobras & 266.847 & 1459 & 268.306 & 99,5 & 0,5 \\
\hline Sabesp & 4.426 & 114 & 4.539 & 97,5 & 2,5 \\
\hline Redecard & 2.865 & 51 & 2.916 & 98,2 & 1,8 \\
\hline Usiminas & 8.422 & 170 & 8.593 & 98,0 & 2,0 \\
\hline TIM & 14.798 & 82 & 14.880 & 99,4 & 0,6 \\
\hline
\end{tabular}

Figura 9 - Relação dos Indicadores Sociais Externos (RISE)

Fonte: Dados da pesquisa

Os dados da Figura 9 evidenciam como os indicadores sociais externos (RISE) foram aplicados no triênio. O índice 8, que representa os tributos pagos pelas empresas (excluídos os encargos sociais), destaca que a BRF foi a empresa com maior percentual, destinando 99,9\% do total de $\mathrm{R} \$ 8,1$ bilhões destinados aos indicadores sociais externos. A seguir, no índice 9, que revela as contribuições para a sociedade, destaca-se a Embraer(2011), com investimento de 5,6\% do total de R\$737 milhões investidos em indicadores sociais externos no triênio.

Os indicadores ambientais apresentados na figura 10 revelam os recursos aplicados no meio ambiente (RISA). Os investimentos relacionados com a produção, calculados no índice 10, destacam qual o percentual que a empresa destinou em ações que minimizam possíveis riscos causados ao meio ambiente pelo processo produtivo. As empresas Cemig e Redecar foram as principais, com 100\% dos investimentos de $\mathrm{R} \$ 272$ milhões e $\mathrm{R} \$ 35$ mil, respectivamente. O índice 11 destaca os investimentos em programas externos, que são projetos voluntários relacionados ao meio ambiente. O Bradesco $(2008 ; 2011)$ surge com maior participação, de $100 \%$ do investimento total de R \$93 milhões. 


\begin{tabular}{|c|c|c|c|c|c|}
\hline Empresa & $\begin{array}{c}\text { Invest } \\
\text { Produç. }\end{array}$ & $\begin{array}{c}\text { Projetos } \\
\text { Internos }\end{array}$ & $\begin{array}{c}\text { Indicad. } \\
\text { Ambient. }\end{array}$ & $\begin{array}{c}\text { Índice 10 RISA } \\
(\%)\end{array}$ & $\begin{array}{c}\text { Índice 11 RISA } \\
(\boldsymbol{\%})\end{array}$ \\
\hline Brasil Foods & 392 & 1 & 393 & 99,8 & 0,2 \\
\hline Cemig & 272 & 0 & 272 & 100,0 & 0 \\
\hline Bradesco & 0 & 93 & 93 & 0 & 100,0 \\
\hline Duratex & 45 & 2 & 47 & 95,5 & 4,5 \\
\hline Embraer & 31 & 0 & 31 & 99,1 & 0,9 \\
\hline Petrobras & 6.552 & 438 & 6.990 & 93,7 & 6,3 \\
\hline Sabesp & 1 & 69 & 71 & 1,8 & 98,2 \\
\hline Redecard & 0 & 0 & 0 & 100,0 & 0 \\
\hline Usiminas & 590 & 3 & 592 & 99,5 & 0,5 \\
\hline TIM & 1 & 0 & 1 & 93,9 & 6,1 \\
\hline
\end{tabular}

Figura 10 - Relação dos Indicadores Ambientais (RISA)

Fonte: Dados da pesquisa

Os dados da Figura 11 detalham a composição dos recursos aplicados em responsabilidade social (RICV). A empresa com maior relação nos investimentos em indicadores compulsórios (encargos sociais, participação nos lucros e resultados e tributos), de acordo com o índice 12, foi a Tim (2011), com 97,1\% do total de $\mathrm{R} \$ 97,8$ bilhões. Já a empresa com melhor posição nos indicadores voluntários, conforme o Índice 13 foi a Embraer (2011) que destinou 23,6\% do total de $\mathrm{R} \$ 3,2$ bilhões.

\begin{tabular}{|c|c|c|c|c|c|}
\hline Empresa & $\begin{array}{c}\text { Invest } \\
\text { Compul. }\end{array}$ & $\begin{array}{c}\text { Invest } \\
\text { Volunt. }\end{array}$ & $\begin{array}{c}\text { Total } \\
\text { Invest }\end{array}$ & $\begin{array}{c}\text { Índice 12 } \\
\text { RICV (\%) }\end{array}$ & $\begin{array}{c}\text { Índice 13 } \\
\text { RICV (\%) }\end{array}$ \\
\hline Brasil Foods & 10.422 & 1.729 & 12.152 & 85,8 & 14,2 \\
\hline Cemig & 24.523 & 1.640 & 26.163 & 93,7 & 6,3 \\
\hline Bradesco & 26.715 & 6.204 & 32.919 & 81,2 & 18,8 \\
\hline Duratex & 2.112 & 228 & 2.340 & 90,2 & 9,8 \\
\hline Embraer & 2.427 & 750 & 3.177 & 76,4 & 23,6 \\
\hline Petrobras & 287.975 & 20.702 & 308.677 & 93,3 & 6,7 \\
\hline Sabesp & 4.945 & 1.075 & 6.020 & 82,1 & 17,9 \\
\hline Redecard & 3.064 & 120 & 3.184 & 96,2 & 3,8 \\
\hline Usiminas & 9.952 & 1.952 & 11.904 & 83,6 & 16,4 \\
\hline TIM & 15.322 & 457 & 15.779 & 97,1 & 2,9 \\
\hline
\end{tabular}

Figura 11 - Relação dos Indicadores Compulsórios e Voluntários (RICV)

Fonte: Dados da pesquisa

A Figura 12 apresenta os dados do total bruto da folha de pagamento, da receita líquida, da participação nos lucros e do resultado operacional. Na relação entre a folha de pagamento e a receita líquida, calculada pelo índice 14, o Bradesco (2011) destaca-se com 38,9\%.

Verifica-se, no índice 15 , a relação da participação nos lucros pelos colaboradores em relação ao resultado operacional obtido no triênio. A Embraer (2011) foi a empresa com maior relação percentual, $12,0 \%$ do resultado operacional de $\mathrm{R} \$ 2,6$ bilhões do triênio.

\begin{tabular}{|c|c|c|c|c|c|c|}
\hline Empresa & $\begin{array}{c}\text { Fopag } \\
\text { Bru. }\end{array}$ & Rec Líq. & $\begin{array}{c}\text { Índice 14 } \\
\text { RIL (\%) }\end{array}$ & Part. Lucr & Res. Oper. & $\begin{array}{c}\text { Índice 15 } \\
\text { RIL (\%) }\end{array}$ \\
\hline Brasil Foods & 10.142 & 72.411 & 14,0 & 79 & 3.537 & 2,2 \\
\hline Cemig & 3.507 & 38.982 & 9,0 & 1.031 & 11.025 & 9,4 \\
\hline Bradesco & 26.827 & 68.912 & 38,9 & 2.192 & 35.553 & 6,2 \\
\hline Duratex & 888 & 7.218 & 12,3 & 78 & 1.610 & 4,9 \\
\hline Embraer & 5.422 & 31.197 & 17,4 & 311 & 2.588 & 12,0 \\
\hline Petrobras & 74.721 & 673.544 & 11,1 & 4.976 & 117.898 & 4,2 \\
\hline Sabesp & 4.219 & 26.493 & 15,9 & 141 & 6.501 & 2,2 \\
\hline Redecard & 402 & 7.799 & 5,1 & 91 & 6.419 & 1,4 \\
\hline Usiminas & 4.861 & 43.748 & 11,1 & 216 & 8.828 & 2,4 \\
\hline TIM & 1.834 & 44.856 & 4,1 & 108 & 2.010 & 5,4 \\
\hline
\end{tabular}

Figura 12 - Relação dos Indicadores Laborais (RIL)

Fonte: Dados da pesquisa 
A Figura 13 apresenta todos os índices calculados a partir dos dados extraídos dos Balanços Sociais das empresas estudadas.

\begin{tabular}{|c|c|c|c|c|c|c|c|c|c|c|}
\hline Índice & BRF & $\begin{array}{c}\mathrm{Ce} \\
\mathrm{Mig}\end{array}$ & $\begin{array}{c}\text { Bra } \\
\text { desco }\end{array}$ & $\begin{array}{c}\text { Dura } \\
\text { Tex }\end{array}$ & $\begin{array}{c}\text { Em } \\
\text { braer }\end{array}$ & $\begin{array}{c}\text { Petro } \\
\text { brás }\end{array}$ & $\begin{array}{c}\text { Sa } \\
\text { besp }\end{array}$ & $\begin{array}{l}\text { Rede } \\
\text { card }\end{array}$ & $\begin{array}{c}\text { Usi } \\
\text { minas }\end{array}$ & TIM \\
\hline $1-$ GPRV & 16,8 & 67,1 & 47,8 & 32,4 & 10,2 & 45,8 & 22,7 & 40,8 & 27,2 & 35,2 \\
\hline $2-$ GPRO & 29,1 & 42,1 & 108,0 & 68,8 & 81,5 & 38,2 & 108,0 & 201,6 & 74,2 & 12,7 \\
\hline $3-$ GPIS & 29,9 & 11,7 & 38,1 & 30,2 & 75,8 & 10,8 & 23,4 & 8,4 & 22,8 & 5,7 \\
\hline 4 -GPIS & 66,9 & 87,3 & 61,6 & 67,9 & 23,2 & 86,9 & 75,4 & 91,6 & 72,2 & 94,3 \\
\hline 5 - GPIS & 3,2 & 1,0 & 0,3 & 2,0 & 1,0 & 2,3 & 1,2 & 0 & 5,0 & 0 \\
\hline $6-$ RISI & 63,4 & 61,2 & 55,2 & 74,9 & 71,9 & 63,3 & 36,8 & 74,5 & 56,2 & 58,4 \\
\hline 7 - RISI & 36,6 & 38,8 & 44,8 & 25,1 & 28,1 & 36,7 & 63,2 & 25,5 & 43,8 & 41,6 \\
\hline $8-$ RISE & 99,9 & 99,2 & 97,6 & 99,7 & 94,4 & 99,5 & 97,5 & 98,2 & 98,0 & 99,4 \\
\hline $9-$ RISE & 0,1 & 0,8 & 2,4 & 0,3 & 5,6 & 0,5 & 2,5 & 1,8 & 2,0 & 0,6 \\
\hline 10 - RISA & 99,8 & 100,0 & 0 & 95,5 & 99,1 & 93,7 & 1,8 & 100,0 & 99,5 & 93,9 \\
\hline 11 - RISA & 0,2 & 0 & 100,0 & 4,5 & 0,9 & 6,3 & 98,2 & 0 & 0,5 & 6,1 \\
\hline 12 - RICV & 85,8 & 93,7 & 81,2 & 90,2 & 76,4 & 93,3 & 82,1 & 96,2 & 83,6 & 97,1 \\
\hline 13 - RICV & 14,2 & 6,3 & 18,8 & 9,8 & 23,6 & 6,7 & 17,9 & 3,8 & 16,4 & 2,9 \\
\hline $14-$ RIL & 14,0 & 9,0 & 38,9 & 12,3 & 17,4 & 11,1 & 15,9 & 5,1 & 11,1 & 4,1 \\
\hline $15-\mathrm{RIL}$ & 2,2 & 9,4 & 6,2 & 4,9 & 12,0 & 4,2 & 2,2 & 1,4 & 2,4 & 5,4 \\
\hline
\end{tabular}

Figura 13 - Relação geral dos índices por empresas (dados em \%)

Fonte: Dados da pesquisa

Em primeiro lugar, destaca-se a Embraer (2011) por ter apresentado quatro índices maiores que as demais empresas (3, 9, 13 e 15). Em seguida, aparecem quatro empresas, todas com melhores resultados em dois índices, sendo elas: a Cemig, com melhores resultados nos índices $1 \mathrm{e}$ 10; o Bradesco (2010; 2011), pelos índices 11 e 14; a Redecard (2011), pelos resultados nos índices 2 e 10; e a Tim (2011), pelos índices 4 e 12. As demais empresas aparecem com um indicador cada, com exceção da Petrobras (2011) que não obteve destaque.

\subsection{Análise do valor adicionado}

A fim de completar a análise dos Balanços Sociais das empresas, foi realizada uma análise da distribuição do valor adicionado com valores representados em milhões de reais.

\begin{tabular}{|c|c|c|c|c|c|c|c|c|c|c|}
\hline Descrição & BRF & $\%$ & Cemig & $\%$ & Bradesco & $\%$ & Duratex & $\$$ & Embraer & $\%$ \\
\hline Colaboradores & 7.260 & 34,6 & 5.071 & 12,8 & 23.332 & 31,0 & 1.258 & 29,5 & 3.940 & 47,9 \\
\hline Governo & 8.015 & 38,2 & 23.180 & 58,6 & 21.896 & 29,1 & 1.493 & 35,0 & 1.086 & 13,2 \\
\hline Terceiros & 4.651 & 22,2 & 4.490 & 11,4 & 529 & 0,7 & 449 & 10,5 & 1.124 & 13,7 \\
\hline Acionistas & 470 & 2,2 & 3.437 & 8,7 & 22.634 & 30,0 & 372 & 8,7 & 674 & 8,2 \\
\hline Retidos & 573 & 2,7 & 3.381 & 8,5 & 6.958 & 9,2 & 689 & 16,2 & 1.407 & 17,1 \\
\hline Total VA & 20.970 & 100 & 39.559 & 100 & 75.349 & 100 & 4.262 & 100 & 8.231 & 100 \\
\hline Descrição & Petrob & $\%$ & Sabesp & $\%$ & Redecar & $\%$ & Usimin & $\$$ & TIM & $\%$ \\
\hline Colaboradores & 53.223 & 11,0 & 4.382 & 28,9 & 494 & 6,3 & 3.881 & 16,8 & 1.668 & 6,8 \\
\hline Governo & 281.929 & 58,3 & 4.560 & 30,0 & 2.940 & 37,5 & 8.771 & 38,0 & 15.114 & 61,8 \\
\hline Terceirc & 38.807 & 8,0 & 2.771 & 18,3 & 24 & 0,3 & 3.560 & 15,4 & 4.770 & 19,5 \\
\hline Acionistas & 30.505 & 6,3 & 990 & 6,5 & 2.653 & 33,8 & 2.417 & 10,5 & 946 & 3,9 \\
\hline Retidos & 78.911 & 16,3 & 2.472 & 16,3 & 1.735 & 22,1 & 4.434 & 19,2 & 1.971 & 8,1 \\
\hline Total VA & 483.375 & 100 & 15.174 & 100 & 7.846 & 100 & 23.062 & 100 & 24.469 & 100 \\
\hline
\end{tabular}

Figura 14- Distribuição do valor adicionado

Fonte: Dados da pesquisa

Os dados da Figura 14 evidenciam que, no geral, o maior beneficiário foi o governo, recebendo, em média, 52,5\% na distribuição; isso ocorre porque a grande maioria dos investimentos 
foi de caráter compulsório (impostos, taxas e contribuições). A empresa que mais destinou parte do seu valor adicionado para o governo foi a Tim, com $61,8 \%$ do total de $\mathrm{R} \$ 24,5$ bilhões gerados e distribuído no triênio.

Como outros beneficiários nessa distribuição, aparecem os colaboradores, com 14,9\%, em média. Nota-se que a empresa que destinou maior percentual para eles foi a Embraer (2011), com 47,9\% dos $\mathrm{R} \$ 8,2$ bilhões de valor adicionado do triênio. Em seguida, com participação média de $14,6 \%$, destacam-se os valores retidos, que representam quanto de riqueza gerada a empresa vem agregando ao seu capital. A Redecard (2011) foi a empresa com maior percentual de valores retidos, com $22,1 \%$ dos $\mathrm{R} \$ 7,8$ bilhões do total adicionado.

Têm-se ainda os acionistas, destacando-se a Redecard (2011), recebendo 33,8\% dos R 7,8 bilhões de valor adicionado. Em seguida, surgem os terceiros, com participação de $22,2 \%$ dos R\$ 21 bilhões adicionados pela BRF.

Levando-se em consideração que a melhor distribuição pode ser feita de forma balanceada, atendendo as partes interessadas (colaboradores, governo e acionistas) e, ao mesmo tempo, reservando parte do capital para futuros investimentos, a melhor distribuição foi realizada pelo Bradesco. Nesta empresa, os principais beneficiários dos $\mathrm{R} \$ 75,3$ bilhões gerados foram os colaboradores com 31\%; acionistas, com 30\%; 29,1\%, para o governo; as menores participações ficaram com lucros retidos $(9,2 \%)$ e terceiros $(0,7 \%)$. Em segundo lugar, destaca-se a empresa Usiminas (2011), com geração de $\mathrm{R} \$ 23,1$ bilhões, a qual destinou $38 \%$ para o governo; $19,2 \%$, retidos; $16,8 \%$, para colaboradores e 10,5\%, para acionistas.

\section{CONSIDERAÇÕES FINAIS}

O objetivo da pesquisa foi analisar o desempenho da gestão sustentável refletido no Balanço Social de dez empresas de diversos setores da economia brasileira no triênio de 2008 a 2010. Para isso, foi utilizada a aplicação dos índices, estudados por Athar Neto (2006), os quais visam facilitar a compreensão dos dados contidos no Balanço Social das empresas. Para ampliar a análise, foi também realizada uma análise da distribuição do valor adicionado.

Verificando os investimentos das empresas nos indicadores sociais, conclui-se que as empresas destinam mais recursos para as áreas externas, não havendo um equilíbrio na distribuição. Além disso, tanto os recursos internos quanto os externos, em sua maioria, estão destinados para cumprimento das obrigações legais. De outra parte, os indicadores ambientais, por enquanto, recebem poucos investimentos das empresas estudadas.

Com base nos diversos indicadores, a melhor empresa foi a Embraer (2011) que investiu 23,6\% em indicadores voluntários e 76,4\% em indicadores compulsórios, do total de $\mathrm{R} \$ 3,2$ bilhões de investimentos no triênio em indicadores socioambientais. Em segundo lugar, o Bradesco investiu $\mathrm{R}$ \$ 32,9 bilhões em indicadores socioambientais no triênio, destinando 18,8\% para os indicadores voluntários e $81,2 \%$ para os indicadores de obrigações legais. Na sequência, aparece a Sabesp (2011), com investimento de $\mathrm{R} \$ 6$ bilhões no triênio, distribuindo 17,9\% para os indicadores voluntários e $82,1 \%$ para os indicadores compulsórios.

Por outro lado, tendo como base a distribuição equilibrada do valor adicionado gerado pelas empresas durante o triênio, a melhor distribuição foi realizada pelo Bradesco, onde os principais beneficiados foram os colaboradores, com 31,0\%; o governo, com 29,1\%; os acionistas, com $30,0 \%$ e 9,2\% retidos, dos $\mathrm{R} \$ 75,3$ bilhões gerados no triênio. A Usiminas (2011) aparece em segunda posição, distribuindo os $\mathrm{R} \$ 23,1$ bilhões e tendo como principais beneficiados os colaboradores, com 16,8\%; o governo, com 38,0\%; 10,5\%, para os acionistas e 19,2\% retidos. Após a melhor distribuição, a Sabesp (2011) distribuiu 28,9\% para os colaboradores; $30 \%$ para o governo; $6,5 \%$ para os acionistas e $16,3 \%$ ficaram retidos.

De modo geral, embora grande parte dos recursos das empresas destinados a ações socioambientais estejam mais direcionados para cumprimento de obrigações legais, a análise mostra que as empresas já estão com o processo de gestão sustentável implantado, tendo em vista que essas

Revista de Gestão Social e Ambiental - RGSA, São Paulo, v. 7, n. 1, p. 53-69, jan./abr. 2013. 
ações iniciais (compulsórias), posteriormente podem avançar para outras voluntárias e mais relacionadas ao meio ambiente, colaboradores e a sociedade.

Diante do exposto, sugere-se que sejam realizados novos estudos, em razão das limitações trazidas pela reduzida amostra desta pesquisa. Assim, além de maior quantidade de empresas, há necessidade de incorporar empresas internacionais estabelecidas em países de cultura, políticas e legislação mais avançadas nessas questões socioambientais. Entende-se que estudos com essa configuração podem contribuir, dadas as possibilidades de análises comparativas de maior abrangência e profundidade.

\section{REFERÊNCIAS}

Alessio, R.(2004) Responsabilidade social das empresas no Brasil: reprodução de postura ou novos rumos? Porto Alegre: Edipucrs.

Almeida, L.N. (2010) Sustentabilidade ambiental como estratégia empresarial na rede Wal-Mart. In: Simpósio de Excelência em Gestão e Tecnologia, 7, Resende. Resende: Associação Educacional Dom Bosco.

Ashley, P.A. (Coord.) (2010) Ética e responsabilidade social nos negócios. (2. Ed.) São Paulo: Saraiva.

Athar Neto, J.M.A. (2006) Modelo para análise do balanço social: o caso Azaléia. Revista Contemporânea de Economia e Gestão, Fortaleza, 4(2), 51-62.

Banco Bradesco S.A. (2011) Balanço social do IBASE. Osasco Recuperado em 20 out.2011, de: <http://www.bancodoplaneta.com.br>.

Banco Bradesco S.A.(2008) Relatório de sustentabilidade. Recuperado em 20 out.2011, de: $<$ http://www.bradescori.com.br>.

Banco Bradesco S.A.(2010) Relatório anual. Recuperado em 20 out.2011, de: <http://www.bradescori.com.br>.

Bellen, H.M. van. (2006) Indicadores de sustentabilidade (2. Ed.) R. Janeiro: FGV.

Brasil Foods S.A. (2011) - BRF. Relatório anual e de sustentabilidade 2009 e 2010. Recuperado em: 20 out.2011, de: <http://www.brasilfoods.com/ri>.

Brasil Foods S.A.(2011) - BRF. Relatório dos auditores independentes sobre as demonstrações financeiras 2010. Recuperado em: 20 out.2011, de: 〈http://www.brasilfoods.com/ri>.

Carroll, A.B. (1991) The pyramid of corporate social responsibility: toward the moral management of organizational stakeholders. Business Horizons, 34(4), 39-48.

Carvalho, G.M.B. (2008) Contabilidade ambiental. Curitiba: Juruá.

Companhia de Saneamento Básico do Estado de São Paulo S.A. - Sabesp. (2011) Demonstrações financeiras 2010. Recuperado em: 20. out.2011, de: 〈http://www.sabesp.com.br〉.

Companhia de Saneamento Básico do Estado De São Paulo S.A. - Sabesp. (2011) Relatório da administração 2009. Recuperado em: 20. out.2011, de: <http://www.sabesp.com.br>. 
Companhia de Saneamento Básico do Estado de São Paulo S.A. - Sabesp. (2011) Relatório de sustentabilidade 2009 e 2010. Recuperado em: 20 out.2011, de: 〈http://www.sabesp.com.br〉.

Companhia Energética de Minas Gerais S.A. - Cemig (2011) Demonstrações financeiras $2009 e$ 2010. Recuperado em: 20 out.2011, de: <http://cemig.infoinvest.com.br>.

Companhia Energética de Minas Gerais S.A. - Cemig (2011) Relatório anual e de sustentabilidade 2009 e 2010. Recuperado em: 20 out.2011, de: 〈http://cemig.infoinvest.com.br〉.

Costa, P.S., Souza, S.D.(2006) Análise empírica da evolução dos indicadores do balanço social no período de 2000 a 2004: o caso da Petrobras. In: Congresso de Controladoria e Contabilidade, 6, Anais... São Paulo, FEA/USP.

Dias, R.(2009) Gestão ambiental. São Paulo: Atlas.

Duratex S.A.(2011) Relatório anual e de sustentabilidade 2010. Recuperado em: 20 out.2011, de: <http://www.duratex.com.br>.

Embraer S.A.(2011) Relatório Anual 2009 e 2010. São José dos Campos, 2010 e 2011. Recuperado em: 20. out.2011, de: 〈http://ri.embraer.com.br>

Ferreira, A. C. S.(2003) Contabilidade ambiental. São Paulo: Atlas.

Goldstein, I.S. (2007) Responsabilidade social. São Paulo: Ática.

Gomes, A.R., Moretti, S.(2007) A responsabilidade e o social. São Paulo: Saraiva.

Igarashi, D.C.C., Igarashi, W., Lima, E.C., Hercos Junior, J.B.(2011) Análise do alinhamento entre o balanço social e o relatório de sustentabilidade dos três maiores bancos em atividade no Brasil. Contexto, 10(18), 34-48, $2^{\circ}$ semestre.

Instituto Nacional de Metrologia, Qualidade e Tecnologia - Inmetro. (2010) ISO 26000: Diretrizes em responsabilidade social. Recuperado: 13 set.2011, de: <http://www.inmetro.gov.br/qualidade/responsabilidade_social/iso26000.asp>

Kroetz, C.E.S. (2000) Balanço social: teoria e prática. São Paulo: Atlas.

Martins, C. M. F., Bernardo, D. C. R., Madeira, G. J. (2002) Origem e evolução do balanço social no Brasil. Contabilidade Vista \& Revista, 13(1), 105-116.

Morimoto, P. Y. A., Zen, M. J. C. M.(2006) Análise do balanço social das empresas de papel e celulose. In: Congresso da Sober, 64. Anais... Fortaleza, Sober.

Moura, L.A.A. (2008) Qualidade e gestão ambiental. (5. ed.) São Paulo: Juarez Oliveira. Petróleo Brasileiro S.A. - Petrobras (2011) Análise financeira e demonstrações contábeis 2010. Recuperado em 20 out.2011, de: <http://www.petrobras.com.br/ri>.

Petróleo Brasileiro S.A. - Petrobras. (2011) Relatório de sustentabilidade 2009 e 2010. Recuperado em: 20 out. 2011, de: <http://www.petrobras.com.br/ri>. 
Pinto, A., Ribeiro, M.(2004) Balanço social: uma avaliação de informações fornecidas por empresas industriais situadas no estado de Santa Catarina. Contabilidade \& Finanças, ano 15, 4(36), 21-34, set/dez.

Ponchirolli, O. (2008) Ética e responsabilidade social empresarial. Curitiba: Juruá.

Portal Brasil.(2011) Índice geral de preços do mercado - IGP-M. Recuperado em: 19 out.2011, de: $<$ http://www.portalbrasil.net/igpm.htm>.

Redecard S.A.(2011) Divulgação de resultados 4T10. Recuperado em: 20 out.2011, de: <http://www.redecard.com.br>.

Redecard S.A.(2011) Relatório anual de sustentabilidade 2009 e 2010. Recuperado em: 20 out.2011, de: <http://www.redecard.com.br>.

Reis, C.N., Medeiros, L.E. (2007) Responsabilidade social das empresas e balanço social: meios propulsores do desenvolvimento econômico e social. São Paulo: Atlas.

Ribeiro, M. de S.(2005) Contabilidade ambiental. São Paulo: Saraiva.

Silva, E.L., Menezes, E.M. (2001) Metodologia da pesquisa e elaboração de dissertação. (2 Ed.) Florianópolis: UFSC/PPGEP/LED.

Souza, M. A. Backes, C. I., Dal Bello, I. L., Parazzoli, M.(2011) Análise de balanço social: estudo em uma instituição religiosa. Contexto, 11(19), 101-113, $1^{\circ}$ sem.

Tenório, F. G. (Coord). (2006) Responsabilidade social empresarial. (2. ed.) R. Janeiro: FGV.

Tim Participações S.A.(2011) Demonstrações financeiras 2009. Recuperado em: 20 out.2011, de: <http://www.timpartri.com.br>.

Tim Participações S.A.(2011) Relatório anual 2009 e 2010. Recuperado em: 20 out.2011, de: $<$ http://www.timpartri.com.br>

Tim Participações S.A.(2011) Relatório de sustentabilidade 2009 e 2010. Recuperado em: 20 out.2011, de: <http://www.timpartri.com.br>.

Tinoco, J.E.P. (2008) Balanço social: uma abordagem da transparência e da responsabilidade pública das organizações. São Paulo: Atlas.

Tinoco, J.E.P. (2010) Balanço social e o relatório da sustentabilidade. São Paulo: Atlas.

Usinas Siderúrgicas De Minas Gerais S.A. - Usiminas (2011) Relatórios anuais 2009 e 2010. Recuperado em: 20 out.2011, de: 〈http://ript.usiminas.com>.

Data da submissão: 02/02/2012

Data da publicação: 30/04/2013 